Ethiopian Journal of Environmental Studies \& Management 7(5): 488 - 498, 2014

ISSN:1998-0507

doi: http://dx.doi.org/10.4314/ejesm.v7i5.3

Submitted: April 14, 2014

Accepted: August 14, 2014

\title{
MAPPING WETLAND CHARACTERISTICS FOR SUSTAINABLE DEVELOPMENT IN HARARE: THE CASE OF BORROWDALE WEST, HIGHLANDS, NATIONAL SPORTS STADIUM AND MUKUVISI WOODLANDS WETLANDS
}

\author{
MHLANGA, B., *MARUZIVA, R. AND BUKA, L. \\ Department of Geoinformatics and Surveying, University of Zimbawe, Box MP 167 Mount \\ Pleasant Harare
}

\begin{abstract}
Wetland ecosystems are under threat from agriculture and urbanisation, affecting water supply and quality in urban areas like the City of Harare. With the need to protect wetlands that remain, the spatial extent of the Highlands, Borrowdale West, Mukuvisi and National Sports wetlands was established. LANDSAT and SPOT Satellite imagery were used to map the spatial extent on the wetlands and to take note of the temporal changes that occurred between 1989 and 2009. Supervised classification was used to classify the images. High resolution Google earth imagery were then downloaded and used as baseline data for mapping the wetlands using the Cowardin wetland classification system 1979 and the Land Capability Classification system for wetness. Maps showing the physical characteristic of the wetlands were then produced. Results indicated that area under wetlands has been shrinking over the years. Using the wetland classification system it was found out that much of the area under wetland should not be used for any other landuse purpose other than wetland protection. However the study found out that urban expansion projects are currently modifying the wetlands. The Highlands wetland has been drained and road construction is currently in progress while a Hotel is under construction on the National sports wetland covering $287012 \mathrm{~m}^{2}$ of the wetland. This study provides information on the current physical state of the wetlands, which can be the basis for wetland protection and management by policy makers and managers.
\end{abstract}

Key Words: Wetland, Spatial extent, Physical characteristics, Classification, Landuse, Protection and Management.

\section{Introduction}

Increasing urbanisation, with the associated land use and land management changes has resulted in the alteration of the hydrology and water chemistry of wetland areas. The changing urban landscape is a characteristic of the global change that is occurring and has become a major issue facing metropolitan cities such as California among others (Wei Je and Murambadoro, 2010). The fast rate of urban development in metropolitan cities has resulted in the reduction in wetlands and their riparian areas. Nigeria's wetland resources are currently being threatened by certain anthropogenic and biogeophysical factors. Notable among such factors are population pressure, rapid urbanization, mining, pollution, uncontrolled tilling for crop production (Orimoogunje et al., 2009). Sarkar and Jain (2008) also recognised that disappearance of wetlands may cause changes in weather conditions,

*Corresponding Author: Maruziva, R.

Email: maruziva00725@alumni.itc.nl 
while lowering the urban subsoil water levels. This has resulted in ground water being recharged by contaminated waste water.

As stated in the Environmental Management Act (2002) wetlands are any areas of marsh, fern, and peat land or whether natural or artificial, temporary or permanent, with flowing or static water, fresh or brackish or salt and include riparian lands adjacent to wetlands. These areas of ecological and economic benefits are protected under the laws of the state. It can however be noted that the damage to and the loss of wetlands is continuing seemingly unabated. A survey by the US department of agriculture found out that urbanisation was responsible for about $58 \%$ of the wetland loss (Ehrenfeld, 2000).

In spite of the protection of wetlands offered by the law, lack of reliable spatial data that adequately delineates urban wetlands and classification system that helps define the goals for wetland management has left gaps in the protection of the resource.

Various wetland classification systems exist based on the characteristics of wetlands. The overall goal of classification is to reduce variability within classes due to differences in natural condition related to factors such as geology, hydrology, and climate. The type of classification system chosen depends on the particular scientific, management, or regulatory application of interest (Detenbeck, 2001). In Zimbabwe, existing and documented classification of wetlands have mainly been applied to suitability of land for agriculture.

With an estimated population of 2.3 million the city of Harare is going through rapid urban growth. The city has grown three time its size and has been growing since independence in 1980 (Kamete, 2002). This has put more pressure on the available resources, such as water, sewage and land for the development of infrastructure such as housing, industry and other necessary amenities. Studies on the temporal changes in wetland size in Harare due to urbanisation were done. Msipa (2009); highlights that urban development has had a direct or indirect impact on the wetlands areas within the city's boundary. However the study did not map the physical characteristics of the wetland areas.

There have been conflicts between Environmental Management Authority (EMA) and the urban authorities over the allocation of residential or commercial stands on wetland areas without conducting proper assessments. EMA through the Ministry of Environment and Natural Resources gazetted list of wetlands. However the lack of data relating to wetland characteristics, ecological state and spatial extends has been a source of the conflict, making it difficult to make informed decision on sustainable utilisation of wetlands for sustainable development. There have been claims that some of the areas gazetted may not be wetlands. This was based on an environmental impact assessment carried out by Plan Afric on a Borrowdale west area gazetted as a wetland (Herald, 2012). The process may have significantly affected developers who had invested in the land before it was gazetted.

Baker et al. (2006) on the other hand asserts that accurate wetland mapping is an important tool for understanding wetland function and monitoring wetland response to natural and anthropogenic actions. The objective of this study is therefore to map the spatial extend of the Wetlands, characteristics, provide data on their physical and ecological conditions and indicate ongoing developments on wetlands. This may empower policy makers to employ spatially based sustainable decision making, which protects the interests of all local communities and the business sector. The study could be useful for the city managers and EMA, to allow for sustainable decisions 
that protects the environment and allows for development.

\section{Methodology \\ Data Collection}

Data on the characteristics of the wetlands were collected form field surveys and orthorectified satellite imagery. Landsat Thematic Mapper (TM) images for March 1989 and Enhanced Thematic Mapper (ETM) images for August, 2000 and the sport image for August 2009 were obtained from the Global Land-cover Facility (GLCF) on Earth Science Data Interface (http://glcf.umiacs.umd.edu.8080/esdi/index/jsp). High resolution JPG Google earth images of 2009 were from the Google earth domain. The two Landsat images were selected to represent two different seasons. The March 1989 image was acquired immediately after the wet season, while the one for August 2000 was acquired during the dry season. Ideally images of different seasons of the same year should be used for better analysis; however the non availability of such data on the free domain made it impossible to achieve that goal, hence the chosen criteria. The three images were chosen because they had a low cloud cover of $>10 \%$ which is easy to analyse. The images were classified to solve the problem of different sensors, and resolutions.

A field ground survey was carried out to collect data on the physical wetland characteristic such as hydric soils, facultative or obligate vegetation that are found in wetlands, evidence of wetness on the surface and soil drainage classes. Transect walks were done and data were collected at random intervals with the aid of a GPS receiver.

The physical attributes of all areas around collected GPS points were compiled on a data sheet. This included vegetation, soil, wetland hydrology indicators and. Human activities on the wetlands were also recorded. From ground survey carried out, all wetlands exhibited presence of hydric soils, moisture on the surface, mottling in the rooting zone and presence of hydrophilic vegetation as wetland characteristics.

\section{Data Processing}

The images were imported into ILWIS 3.8. Map lists were then created and used in the supervised classification process. Main land cover types used in the classification scheme were permanent wetland, seasonal wetland, tree vegetation and non wetland. Considering that the study area is an urban setting, high density of pixel information necessitated that the supervised classification be applied. A sample set was prepared and training pixels were assigned to the land cover classes. Maximum likelihood classification algorithm was the chosen method since it considers variability within classes.

Google earth images were georeferenced in ArcGIS 9.3 with a RMS of 0.6. Mosaicking was then applied to the images since they were extracted scene by scene at the highest possible resolution. This was done so as to have high resolution imagery as a baseline for mapping wetland characteristics.

\section{Tasselled Cap Transformation}

A tasselled cap transformation of the 1989 Landsat 5 TM was carried out ArcGIS 9.3. This was done to calculate the wetness indices in the study area. Landsat 5 TM data were converted to the equivalent of the Landsat 7 ETM+. This was done to enable the user to apply the tasselled cap coefficients developed by (Huang et al., 2002). The expression below was used in the conversion process.

\section{DN7 $=\left(\right.$ slope $_{\lambda} *$ DN5) intercept $\lambda_{\lambda}$}

The DN values were then converted to radiance data. The radiance data were in turn converted to reflectance. This was done to eliminate atmospheric variables that cause noise and affect analysis by introducing errors. The reflectance is referred to as the Top of Atmosphere (TOA) reflectance. 
Tasselled cap indices were then calculated. Mainly the tasselled cap wetness index was used as it gives a measure of the wetness factor in the study area, the Table 1: Tasselled cap coefficients

\begin{tabular}{lllllll}
\hline Index & Band 1 & Band 2 & Band 3 & Band 4 & Band 5 & Band 7 \\
\hline Brightness & 0.3561 & 0.3972 & 0.3904 & 0.6966 & 0.2286 & 0.1596 \\
Greenness & -0.3344 & -0.3544 & -0.4556 & 0.6966 & -0.0242 & -0.2630 \\
Wetness & 0.2626 & 0.2141 & 0.0926 & 0.0656 & -0.7629 & -0.5388 \\
\hline
\end{tabular}

Adapted from Huang et al. (2002)

The equation for calculating the tasselled cap wetness index is given below-:

Tasselled cap $=\left(\operatorname{coeff}_{1} *\right.$ band $\left._{1}\right)+\left(\operatorname{coeff}_{2} *\right.$ band $\left._{2}\right)+\left(\right.$ coeff $_{3} *$ band $\left._{3}\right)+\left(\operatorname{coeff}_{4} *\right.$ band $\left._{4}\right)+($ coeff $_{5} *$ band $\left._{5}\right)+\left(\operatorname{coeff}_{7} *\right.$ band $\left._{7}\right)$

The tasselled cap wetness index indicates the soil moisture, distribution of saturation zones and depth of water table (Melesse et al., 2007). It is therefore applicable to wetland mapping considering the relatively high water table and presence of hydrophytic vegetation in wetlands.

\section{Photo Interpretation and Wetland Classification}

Photo interpretation was used to determine or delineate the physical characteristics and classify the wetland sites in conjunction with field data collected on the characteristics of the wetlands. These were used as a basis upon which proper classification of the wetlands was done. Two classification systems used were; The Land Capability Classification used for assessing land utility limit because of wetness, and the Cowardin Wetland Classification System (Cowardin, 1976).

Using the collected field survey data and the guidelines for classification of wetlands, maps showing wetland classes were produced by interpolating areas that had the same characteristics. Soil and vegetation species were the main characteristics that were used in the classification. The wetland areas were then digitised in an ArcGIS. completed in 1987. greenness and brightness were not relevant and were not used. The Huang et al., (2002) coefficients used are given below.

\section{Results and Discussion Spatial Extent of Wetlands Extent of Wetness}

Using the Tasselled cap wetness index, the Borrowdale and National sports wetlands indicated low levels of wetness compared to the Highlands and Mukuvisi wetlands. Results of applying the tasselled cap transformation are shown on figure 1. Dark shades of blue indicate high wetness values, while the lighter blue indicates low wetness values. Most vegetated areas with healthy trees indicate high wetness, however moist soil also show moderately high wetness. Values above zero (0) indicate high wetness while those in the negative range indicate low wetness. It can be noted that the Borrowdale wetland and the National sport wetland indicate low values of wetness. Patches of dark blue indicate presence of moisture. Much of the national sports wetland indicates low levels of wetness which can be attributed to the construction of the National Sports Stadium close to the wetland which was

The highlands wetland indicated high wetness compared to the Borrowdale wetland to the north. This probably was because it had low level of disturbance compared to the latter. The Borrowdale wetland may also have been affected by urban agriculture due to its lower wetness value. However to the north east of the Mukuvisi wetland there is an indication of higher wetness, while the south western part indicates low wetness. The lower part is in a game reserve area. 


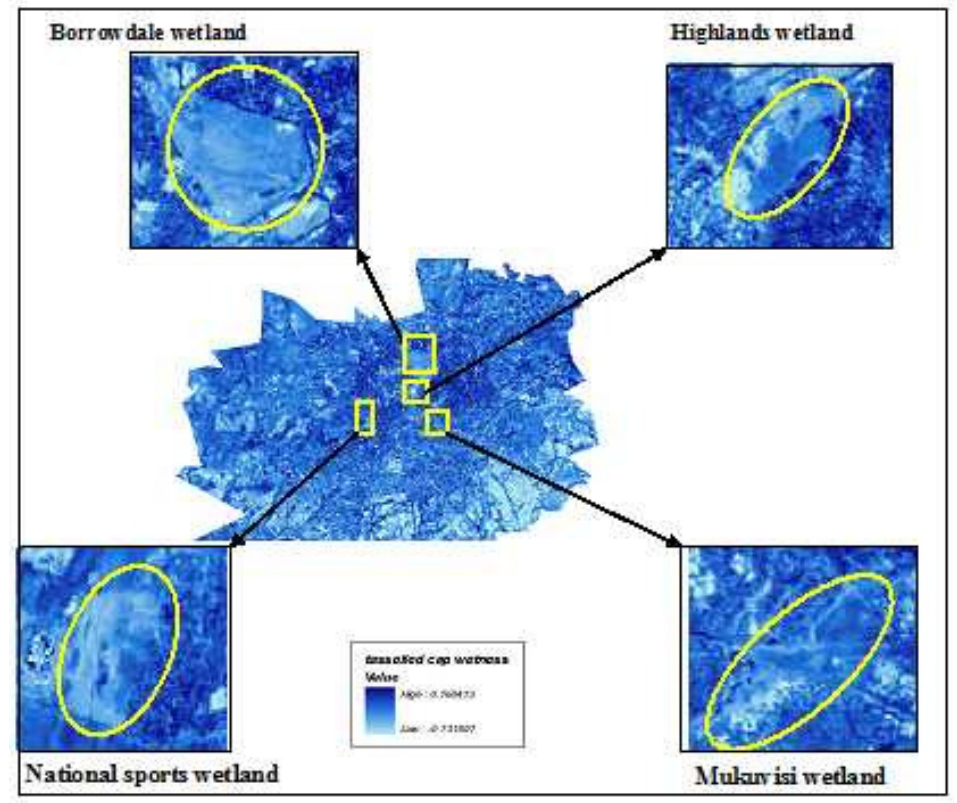

Figure 1: Tasselled cap wetness index

\section{Changes in Wetland Size}

During classification most residential areas were classified as vegetation forest due to the high density of tree cover. This was one challenge encountered during the interpretation of the data. It was noted that vegetation in residential areas showed to be health hence did not interfere with the Mukurisi wetland 1989
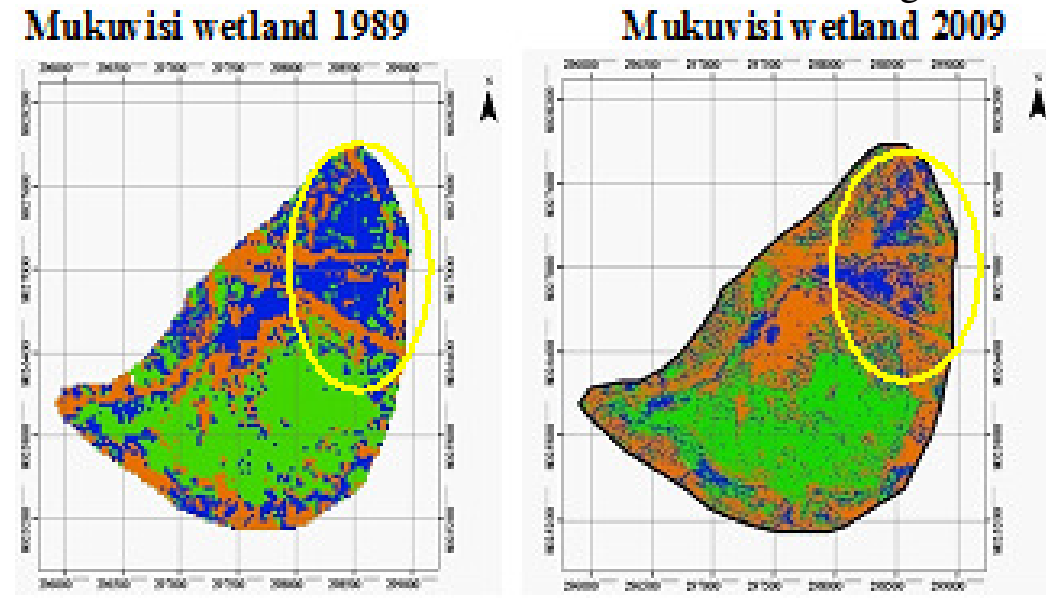

wetland class, except where watering was done.

The Mukuvisi wetland which supplies water to the Mukuvisi woodland nature reserve appears to have shrunk in size between 1989 and 2009. The extent of the wet area has reduced in size as shown in figure 2.

Figure 2: Mukuvisi wetland extent

Upstream farming activities around the Honeydew farm have reduced water flows into the wetland area. Considering the abstraction of borehole water for agriculture activities, water flow from the upland has significantly reduced. Expansion of the adjacent Msasa industrial area may also be encroaching into this important wetland area. This has seen a reduction in the size of wetland patches in the nature reserve, and 
may significantly affect water levels in the impoundment that supplies animals with water.

In 1989 the Borrowdale and Highlands wetlands covered a large area. However by 2000 there was an indication that the extent of the wetland had reduced in size. Urban expansion and agriculture were attributed as the main causes of the decrease in size of the wetland area. Field survey showed that cultivation had already begun during the dry season. By the year 2009 the wetland had become highly fragmented. This was mainly attributed to the expansion of urban agriculture and residential development in open wetland areas.

The National Sports wetland increased in area between the period 1989 and 2009. Though it is highly fragmented, more patches of wetland can be noted on the 2009 map compared to the former. This may be attributed to the recovery of the wetland post construction period of the National Sports Stadium which was completed in 1987. However from the field survey, the wetland is currently under threat from agriculture and ongoing development on the site.

It may be noted that the greatest threat to the wetlands on the study sites is mostly urban developments. Areas under wetlands exhibit non wetland characteristics because they have been drained. These wetlands are island of endogenic species where urban development has introduced exogenic species of flora and fauna. When they shrink in size it affects the natural habitat for most aquatic life which they support.

\section{Mapping Physical Characteristics}

From ground survey carried out, all wetlands exhibited presence of hydric soils, moisture on the surface, mottling in the rooting zone and presence of hydrophilic vegetation as wetland characteristics.

\section{Wetland Classification}

Land Capability Classification for Wetlands

Using Land Capability Classification system wetland classes' w1, w2 and w3 indicate the wetness characteristic of the wetland. The w1 class generally indicates no sign of mottling in the topsoil, hence low moisture in the subsoil. The w2 normally contains sedges and grass species which are indicative of wet conditions e.g. Londetia simplex, Paspalum commersoni, Eragrostis capensis and Alloteropsis semialata. However w3 wetland is defined as land that is saturated to within $15 \mathrm{~cm}$ of the surface for major part of the rainfall season and very wet throughout the year.

Mukuvisi wetland showed that area under moist conditions for most of the season was small. However field observations indicated that the w3 wetland type area provided perennial flow to the Chiraura River that passes through the nature reserve. The area under w2 wetland class indicates significant interference with agriculture and therefore should not be used for urban development. Based on this classification system urban planners may develop on w1 wetlands but exempt all class $\mathrm{w} 3$ and $\mathrm{w} 2$ areas from further development to protect the wetlands. The developments from Msasa industrial area seem to be encroaching into the w2 of the wetland area, threatening wildlife and aquatic life that is being supported downstream. It was noted that the wetland support migratory bird species that are an attraction in the nature reserve. Figure 3 shows wetland classes of the Mukuvisi wetland. 


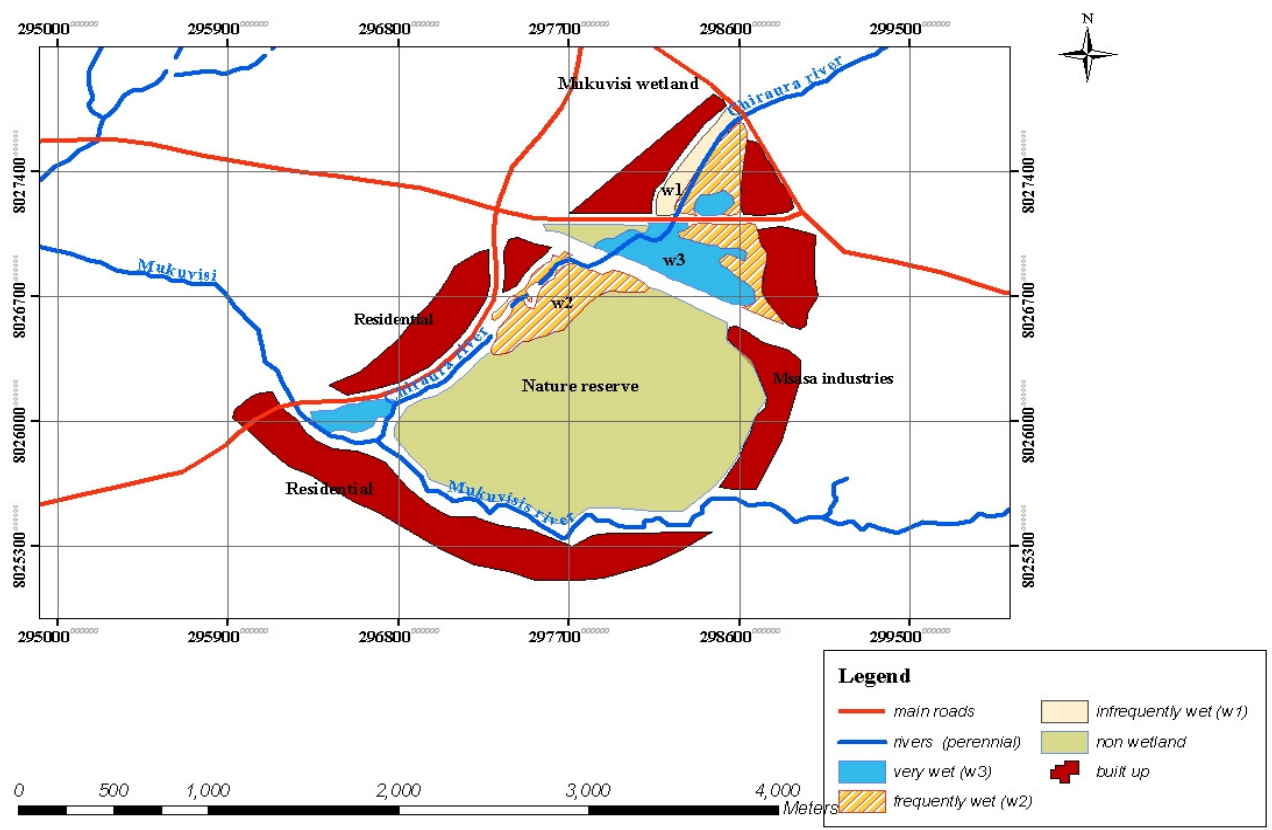

Figure 3: Wetland classification map of Mukuvisi wetland

The Borrowdale wetland had been affected by urban development that has reduced its size. A narrow strip of land constitute the permanently waterlogged area, however it was noted that this part of the wetland had the greatest plant and animal species. Much of the wetland falls under the w2 and w3 classes.

From field observation, it was noted that much of Highlands wetland area was under urban agriculture, however using the classification system shows there is significance hindrance during much of the season. The fringes of the wetland area would be suitable for residential purposes while a small portion of the wetland falls under the w3 class. Much of that part of the wetland shows no signs of disturbance because it is perennially water logged. Obligate vegetation was noted in the field survey.

The National Sports wetland area also indicates high wetness level with significant limitations to agriculture. Though it has been affected by human activities evidence of hydrophytic vegetation was present in patches. Much of the wetland is under the w2 wetland class, thus it presents significant limitation to both agriculture and urban development. It was observed that the wetland has black soils which expand and posed danger to buildings. Using this classification system it was concluded that the area should therefore be utilised as a nature reserve that extend to the adjacent Monavale Vlei, home for different birds species and wetland site.

\section{Cowardin Wetland Classification System}

Under the Cowardin classification system one main wetland type emerged in the study area, the palustrine wetland. The Palustrine system includes all freshwater wetlands (such as marshes, bogs, and swamps) dominated by trees, shrubs, emergent herbaceous plants, floating leaved and submerged plants, mosses and lichens. The emergent subclass is the dominant subclass, with its subdivision being persistent and non-persistent.

It was noted that much of the wetlands in the areas under study are emergent non persistent. This represents drying of the wetland during the dry season with facultative vegetation remaining. The Palustrine emergent class indicates areas with 
vegetation that remain standing during the dry season. This type of vegetation occurs on swampy areas and includes bulrushes, reeds and cattails. Using this classification system it was noted that transforming these wetlands into other land uses would likely reduce water supply to most aquatic organisms that depend on the conditions that prevails there in. Below is a map of the four wetlands mapped using the Cowardin classification system.

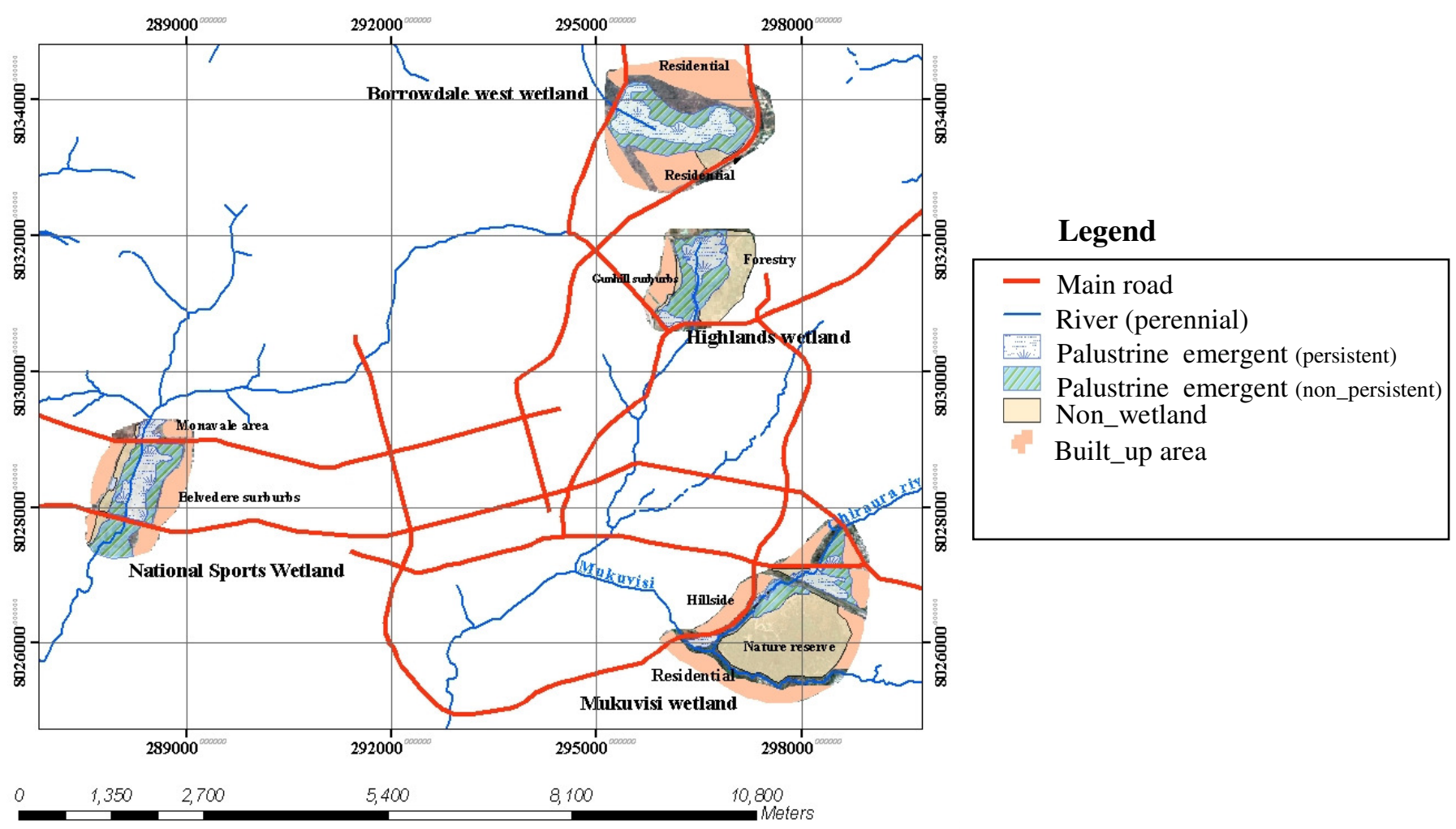

Figure 4: Cowardin wetland classification map

From figure 4 above it can be noted that the emergent wetland area form the core of the wetlands, these provide perennial water flow to the stream nearby. Developments that are made on these wet areas would disturb the hydrology of the area. It is therefore necessary to protect the areas from further developments. It is important to note that both Cowardin and Land capability classification systems identify same areas as unsuitable for urban development. The palustrine covers almost same areas as w2 and $\mathrm{w} 3$ in Land capability with persistent covering $\mathrm{w} 3$ and non - persistent, w2.

\section{Mapping Development on Wetlands}

During the field survey it was noted that all the wetlands under study had been significantly disturbed by illegal urban agriculture and construction. More so the Borrowdale west wetland had excavation pit and survey marks that indicated preparation for development. Road construction had already commenced in Highlands wetland area, inspite of the protection status accorded the wetland under the Environmental Management Act.

Figure 5 show developments that have recently be carried out on Highlands wetlands. 

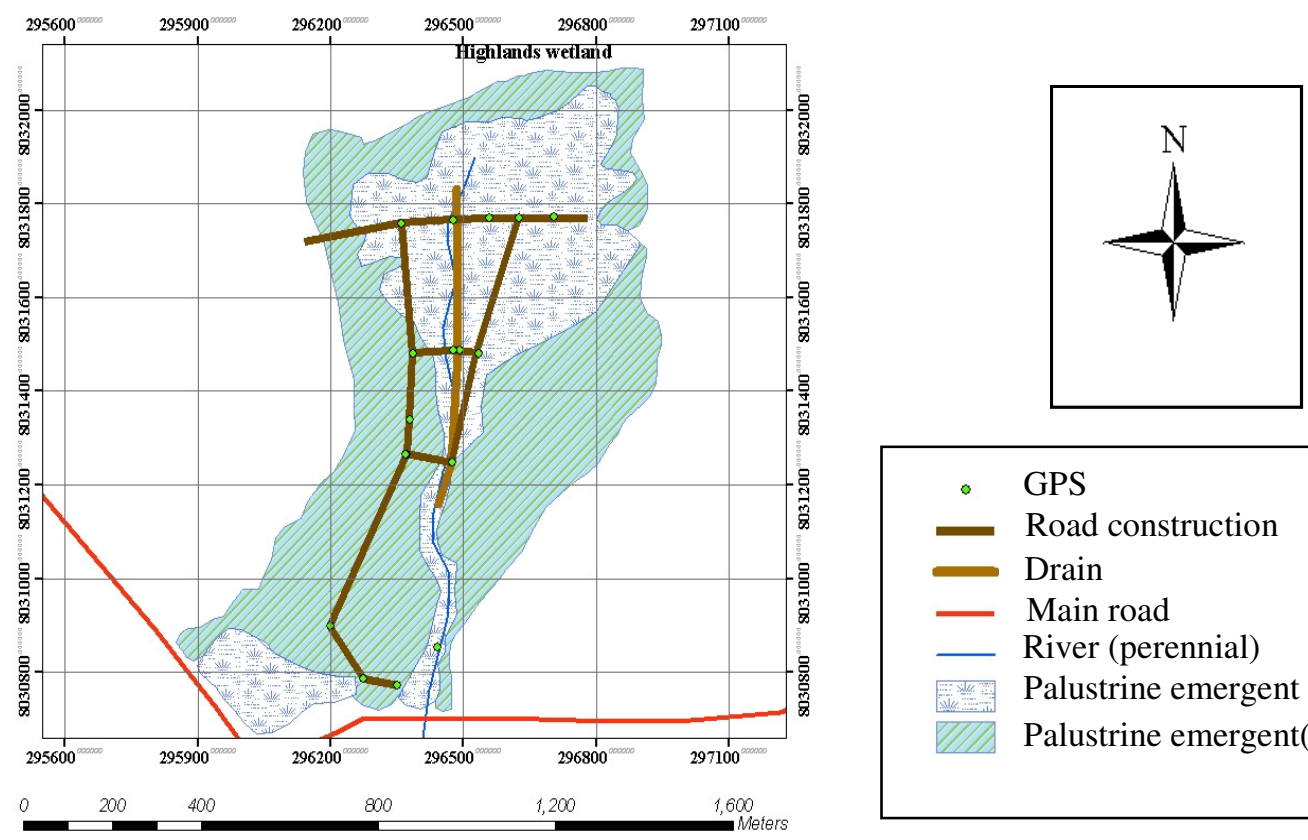

- GPS

Road construction

Drain

Main road

- River (perennial)

Palustrine emergent (persistent)

Palustrine emergent(non_pesistent)

Figure 5: Construction activities on the Highlands wetland

It was noted that in an effort to erect building on the wetland, a drain $1 \mathrm{~m}$ deep was excavated through the wetland to drain water. In essence this wetland is lost as draining it will modify its ecological and physical attributes. Compaction of the soil during road constructions means that underground water

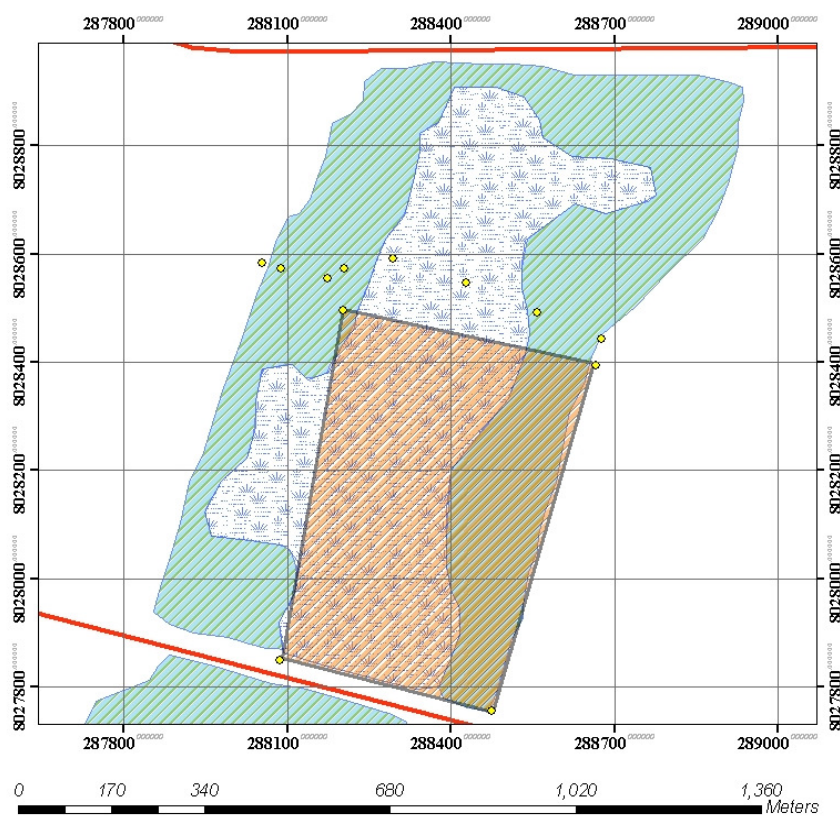

movement will be restricted affecting the hydrology of the wetland. It can be concluded that application of the wetland classification would have helped in protecting the wetland from further urban development if restriction to such use for palustrine wetland would be enforced.

Figure 6: Construction activities on the National sports wetland 
On the national sport wetland area a large Hotel project is on its way towards completion. Much of the hotel is sited on palustrine emergent persistent wetland area that is perennially water logged covering an area approximately $287012 \mathrm{~m}^{2}$. As indicated on the figure 6 above, hotel site consumed a large portion of the wetland. Construction of hotel on this site will likely have downstream effect on the water quality as well as the quantity.

From the mapping of urban developments on wetlands, it becomes apparent that not much consideration was put on the importance of wetlands. By draining, the wetland in order to construct shows that the wetlands characteristics were never taken into account during impact assessment of the construction projects. This study confirms findings by Ehrenfeld (2000) that urbanisation was responsible for 58\% wetland loss and the study by Orimoogunje, et al. (2009) which identified infrastructural development, sewage and solid waste disposal and cultivation as having been and continued to be undertaken in Ilesa wetlands. Classification and mapping physical characteristics of wetland provide essential tools for sustainable decisions that protect the sensitive areas of the wetland.

\section{Conclusions}

The Mukuvisi, Borrowdale, National sports and Highlands wetlands are reducing in extend due to urban development as noted between the periods 1989 and 2009 .

Urban agriculture is affecting the ecological status and level of wetness of the wetlands studied.

Despite being protected under legislation wetland utilisation is continuing seemingly unabated, with construction work currently taking place on the Highlands and National Sports wetland areas.
Existing wetlands need to be classified and priorities given for the protection of sensitive areas of the wetland.

The study has proved that by mapping the spatial extend of the wetlands, their characteristics and providing data on their physical and ecological conditions, sustainable decisions that protects the environment and allows for development can be achieved.

\section{Recommendations}

In light of the findings made from this study, the following recommendations need to be considered:-

- Further research is recommended on the above stated and other wetlands in the city of Harare, to necessitate protection of these sensitive ecosystems by the local authorities.

- Before a property can be developed, the developer should be required determine whether wetlands are present, and to identify or delineate the extent of these wetland borders using : 1) wet conditions, 2) wet or hydric soils with mottling or gray layers, and 3) vegetation that is adapted to wet soils as parameters.

- A wetland classification system based on environmental protection and sustainable development principles while adapting to local conditions should be developed, so as to have a clear criteria for wetland use and protection.

- A database for all wetlands and their characteristics within Harare should be developed to necessitate scientific decision making on how to make use of wetland sustainably.

- A permit system should be developed for all development on wetlands to ensure that no unauthorised activities are carried out on wetland areas under protection. 


\section{References}

Baker, C., Lawrence, R., Montagne, C. and Patten, D. (2006). mapping wetlands and riparian areas using landsat etm1 imagery and decision-tree-based models, WETLANDS, Vol. 26, No. 2, June 2006, pp. 465-474, The Society of Wetland Scientists

Cowardin, L.M. (1979). the Cowardin system of wetland classification (1979) and the national wetlands (NWI); extension.unh.edu/resources /files. 0807-2012

Detenbeck, N. (2001). Wetland classification: a first step. cpcb.ku.edu/detenbeck.pdfs.08-07-2012

Ehrenfeld, G. (2000). Evaluating wetlands within an urban context. www.eisevier.com; New jersey, USA. 08-07-2012

Environmental Management Act (2002). www.zela.org. acquired 08-07-2012

Huang, C., Wylie, B., Yang, L., Homer, C., and Zylstra, G. ( 2002). Derivation of a tasselled cap transformation based on Landsat7 at-satellite reflectance. International Journal of Remote Sensing,

Kamete, A. Y. (2002). Governance for Sustainability? Balancing social and environmental concerns in Harare. Chr. Michelsen institute, Bergen, Norway, http://www.cmi.no/public/pub2002

Melesse, M. Qihao, W. Thenkabail, S. and Senay, B. (2007). Remote sensing sensors and applications in environmental resources mapping and modelling, wwW.mdpi.org/sensors acquired 15-08-2012

Msipa, M. (2009). Land use changes between 1972 and 2008 and current water quality of wetlands in Harare, Zimbabwe.

Orimoogunje, O., Oyinloye, O.R. and Soumah, M. (2009). Geospatial Mapping of Wetlands Potential in Ilesa, South-western Nigeria; SDI in Municipality and Natural Resources Management. www.oauife.edu.ng acquired 08-07-2012

Sarkar and Jain (2008). Using Remote Sensing Data to Study Wetland Dynamics-A Case Study of Harike Wetland

Wei ji, Murambadoro, D. (2010). Digital earth: quantifying urban landscape changes for impact analysis; www.digitalearth-isde.org/bulgaria. acquired 08-07-2012 